\title{
Self-Assembled ROS-Sensitive Polymer-Peptide Therapeutics Incorporating Built-in Reporters for Evaluation of Treatment Efficacy
}

Zeng-Ying Qiao,,$^{\dagger}$ Wen-Jing Zhao, ${ }^{\dagger, \$}$, Yong Cong, ${ }^{\dagger}$ Di Zhang, $^{\dagger}$ Zhiyuan $\mathrm{Hu}^{\dagger}$ Zhong-Yu Duan ${ }^{\ddagger}$ and Hao Wang ${ }^{\dagger} *$

${ }^{\dagger}$ CAS Center for Excellence in Nanoscience, CAS Key Laboratory for Biological Effects of Nanomaterials and Nanosafety, National Center for Nanoscience and Technology (NCNST), Beijing, 100190, China.

Email: wanghao@nanoctr.cn

*School of Chemical Engineering \& Technology, Hebei University of Technology, Tianjin, 300130, China.

$\S$ These authors contributed equally to this work.

KEYWORDS: self-assembly, peptide, ROS-sensitive, $\operatorname{poly}(\beta$-thioester)s, cancer 


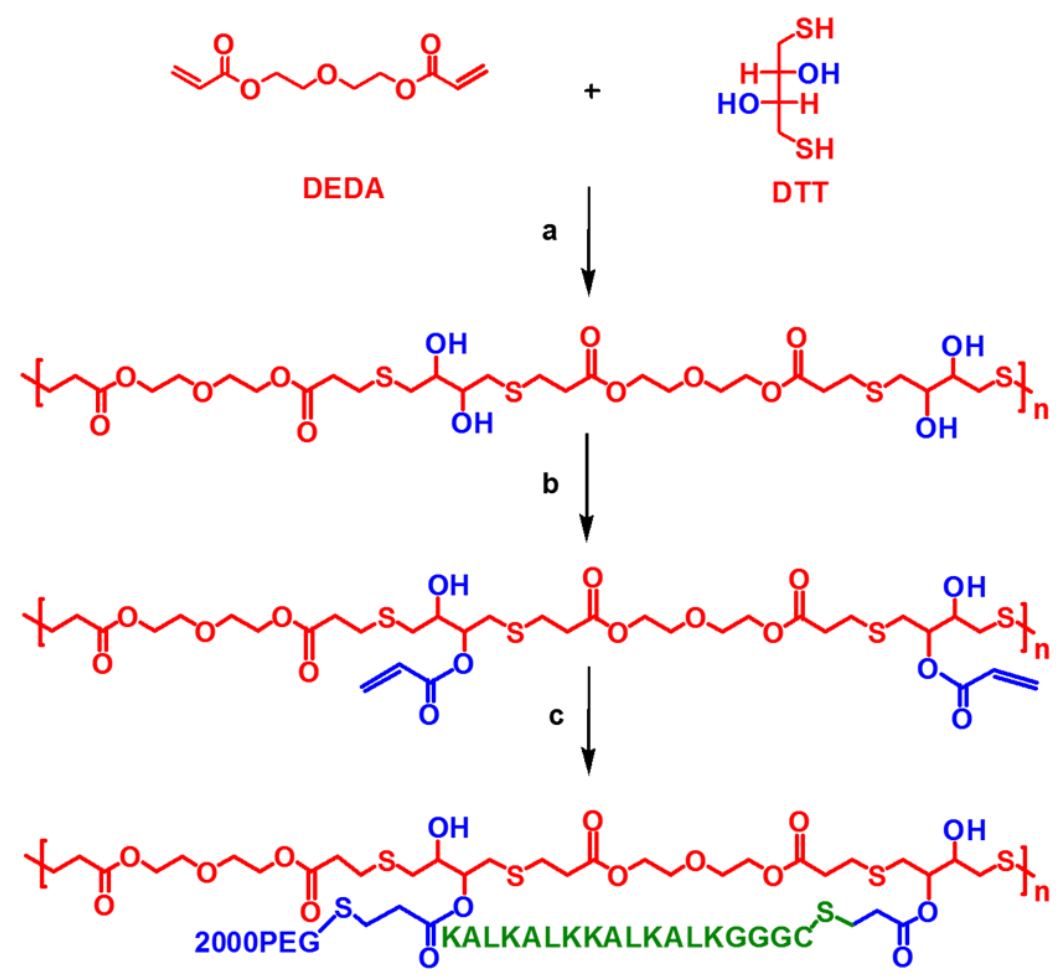

Scheme S1. Synthesis routs of the ROS-sensitive D-P-K nanoparticles. (a) Michael-type addition, $\mathrm{Et}_{3} \mathrm{~N}$, DMSO, $50{ }^{\circ} \mathrm{C}, 3 \mathrm{~d}$. (b) Acryloyl chloride, $\mathrm{Et}_{3} \mathrm{~N}, \mathrm{DMSO}$, 25, 1d. (c) CGGG(KLAKLAK) $)_{2}$ and PEG2000-SH, Michael-type addition, $\mathrm{Et}_{3} \mathrm{~N}$, DMSO, $50{ }^{\circ} \mathrm{C}, 2 \mathrm{~d}$. 


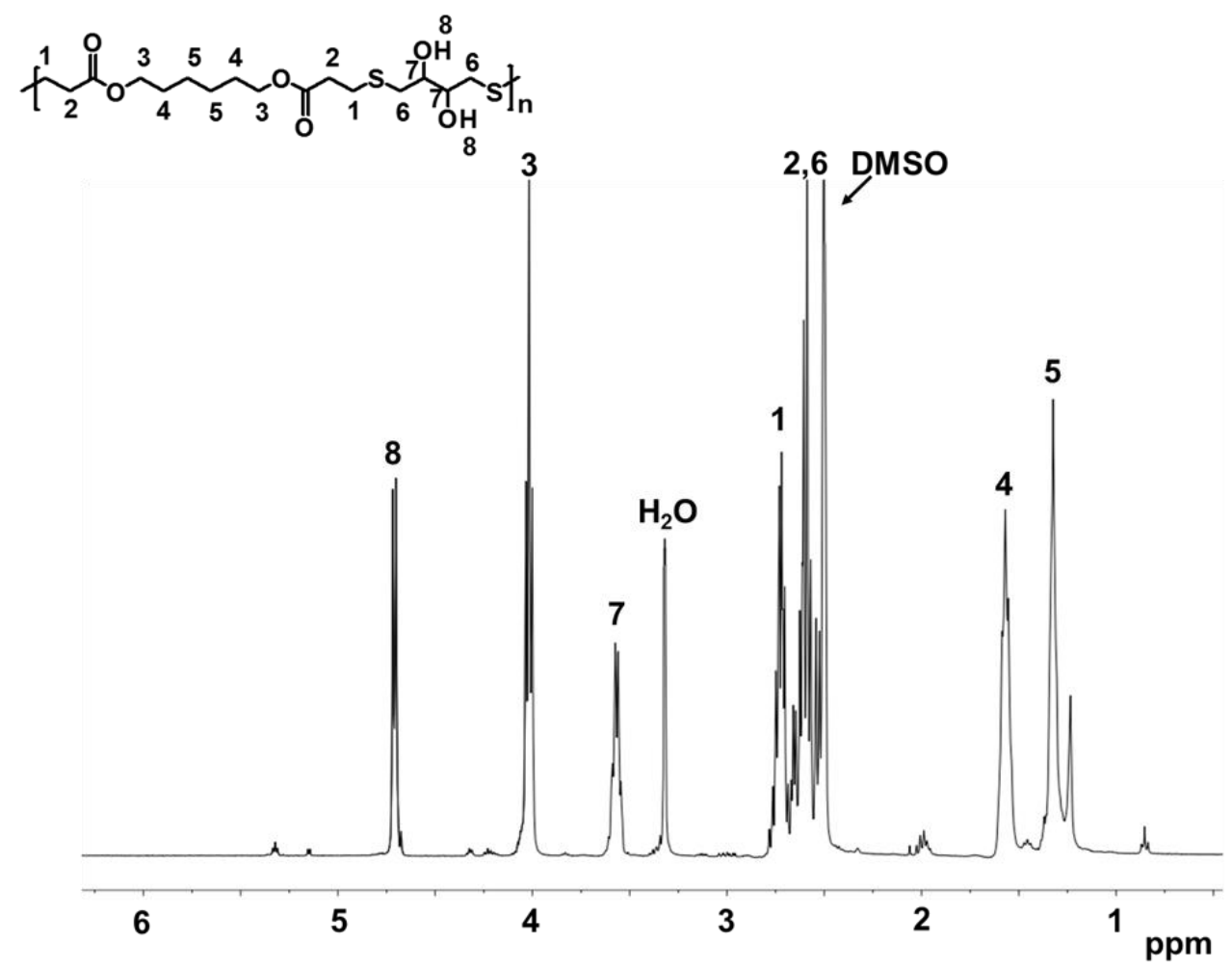

Figure S1. ${ }^{1} \mathrm{H}$ NMR spectrum of copolymers poly( $\beta$-thioester)s $\mathbf{H}$ in $\mathrm{d}^{6}$-DMSO.

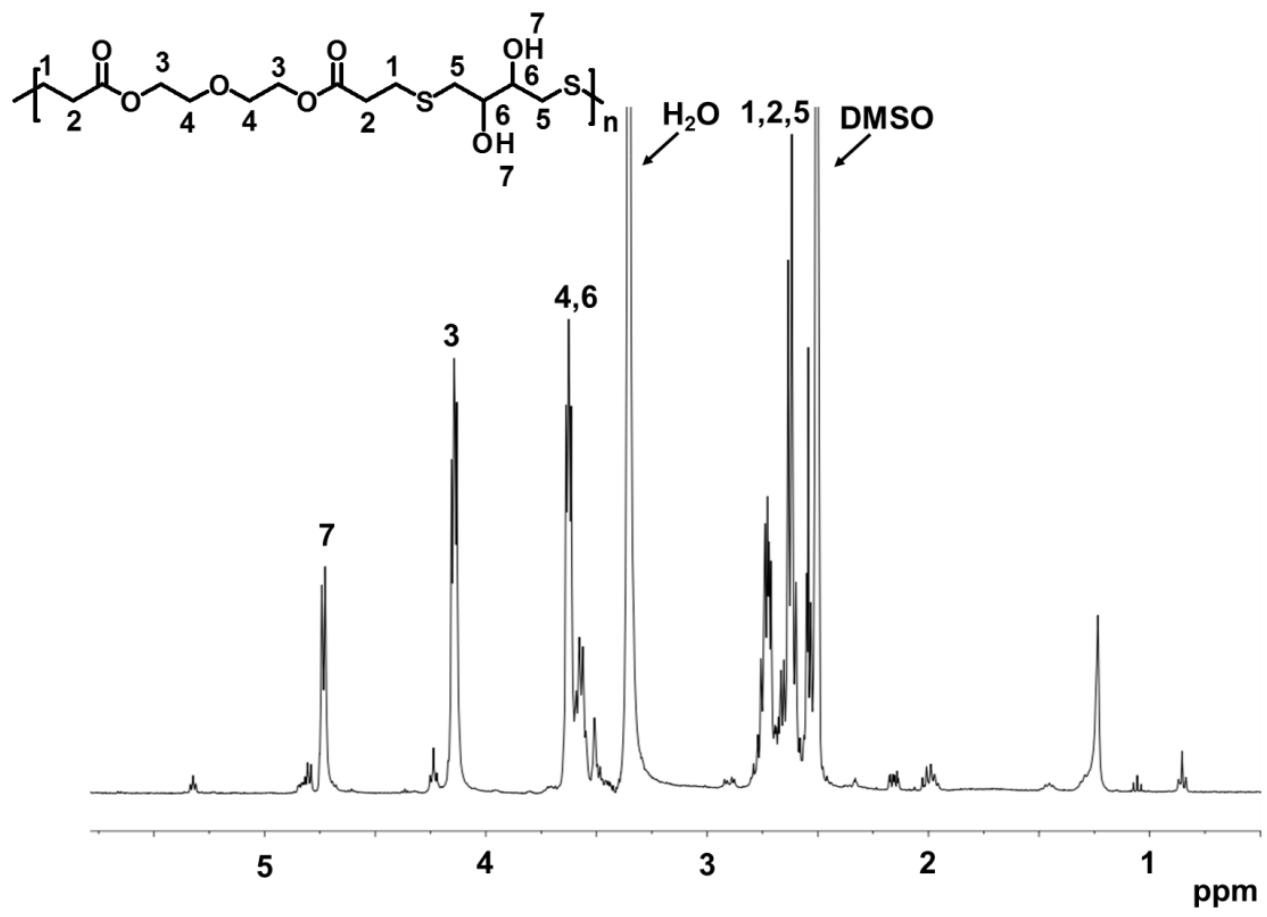

Figure S2. ${ }^{1} \mathrm{H}$ NMR spectrum of copolymers poly( $\beta$-thioester)s $\mathbf{D}$ in $\mathrm{d}^{6}$-DMSO. 


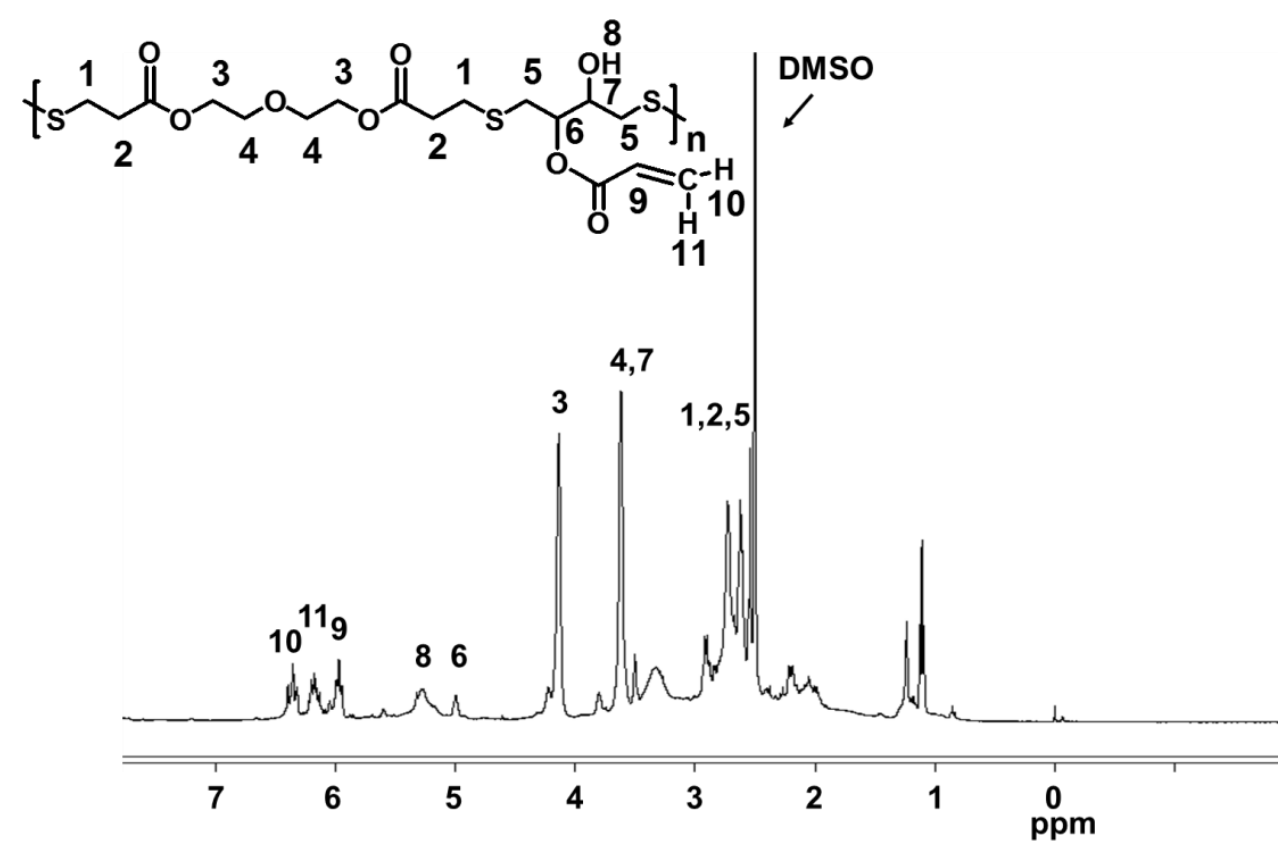

Figure S3. ${ }^{1} \mathrm{H}$ NMR spectrum of copolymers acryl-D in d $\mathrm{d}^{6}$-DMSO.

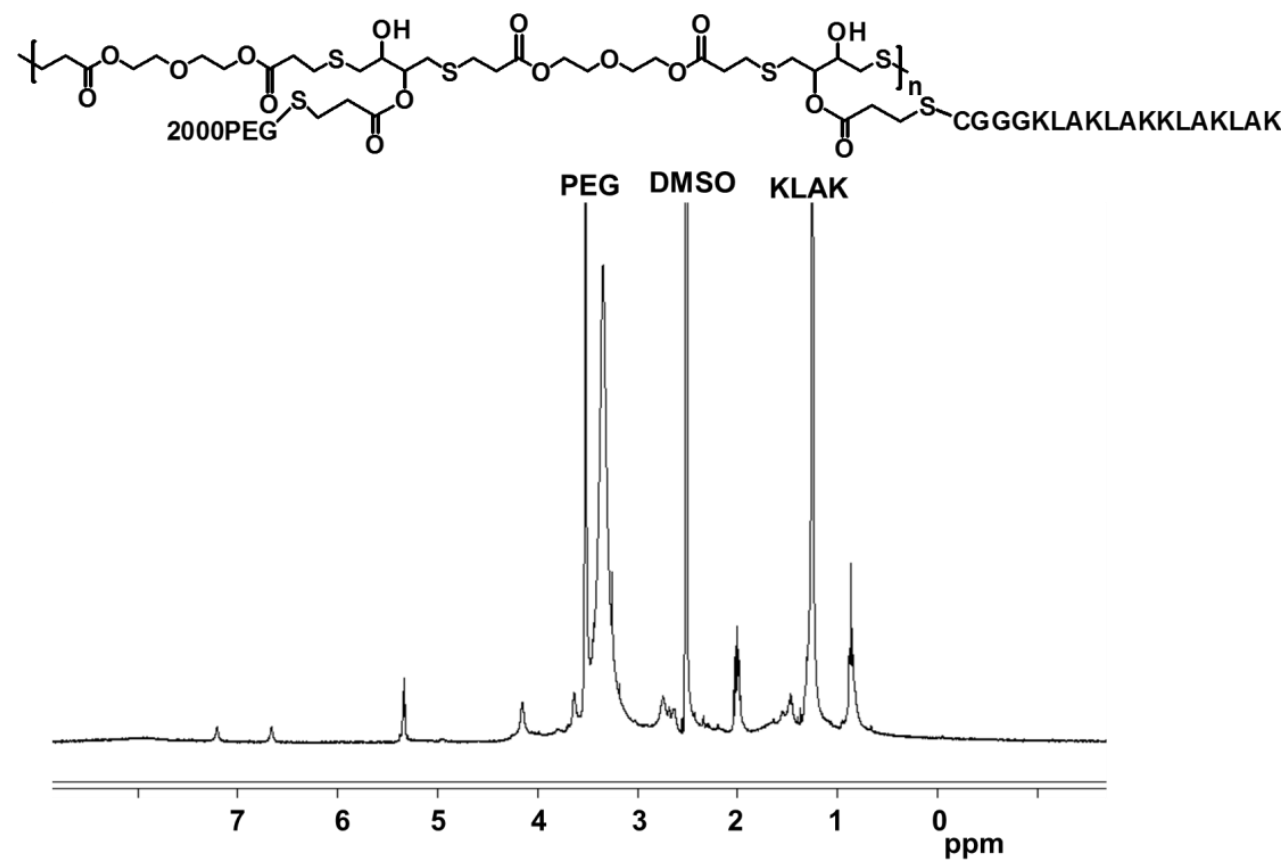

Figure S4. ${ }^{1} \mathrm{H}$ NMR spectrum of copolymers D-P-K in $\mathrm{d}^{6}$-DMSO. 

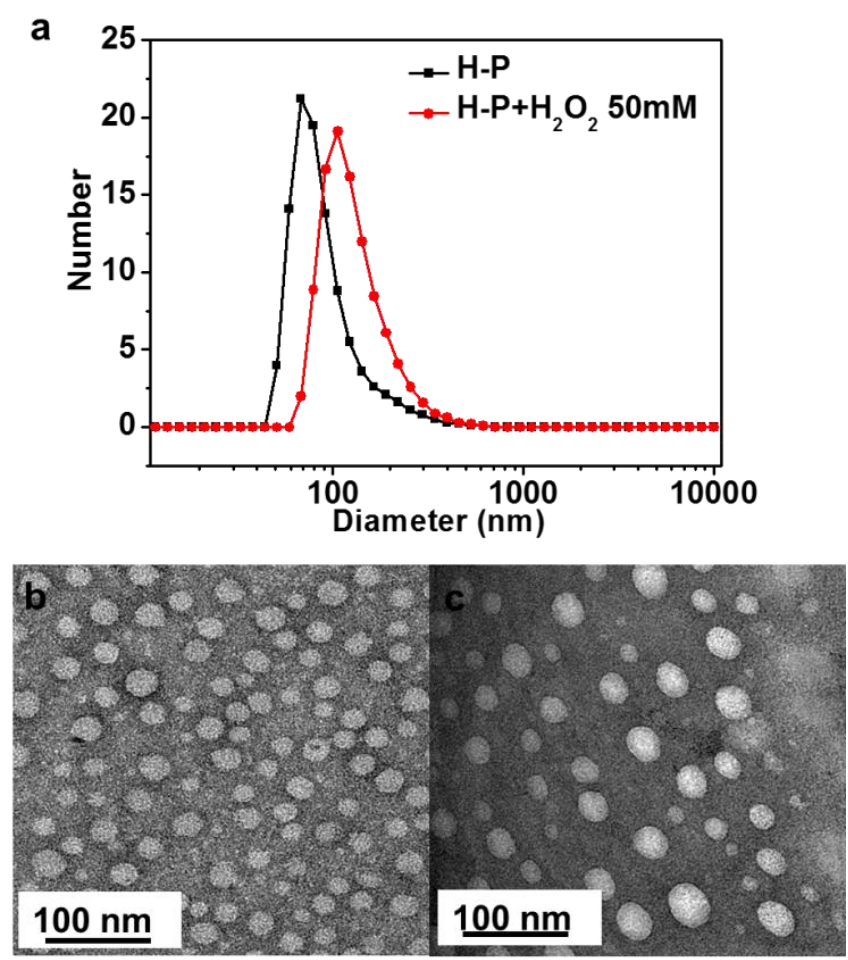

Figure S5. The self-assembly and ROS sensitivity of H-P nanoparticles. (a) Number size distribution of $\mathbf{H}-\mathbf{P}$ nanoparticles in $\mathrm{PB}$ solution and in $50 \mathrm{mM} \mathrm{H}_{2} \mathrm{O}_{2}$ measured by DLS. (b) The TEM images of the H-P nanoparticles. (c) The TEM images of the H-P nanoparticles after incubation with $50 \mathrm{mM} \mathrm{H}_{2} \mathrm{O}_{2}$.

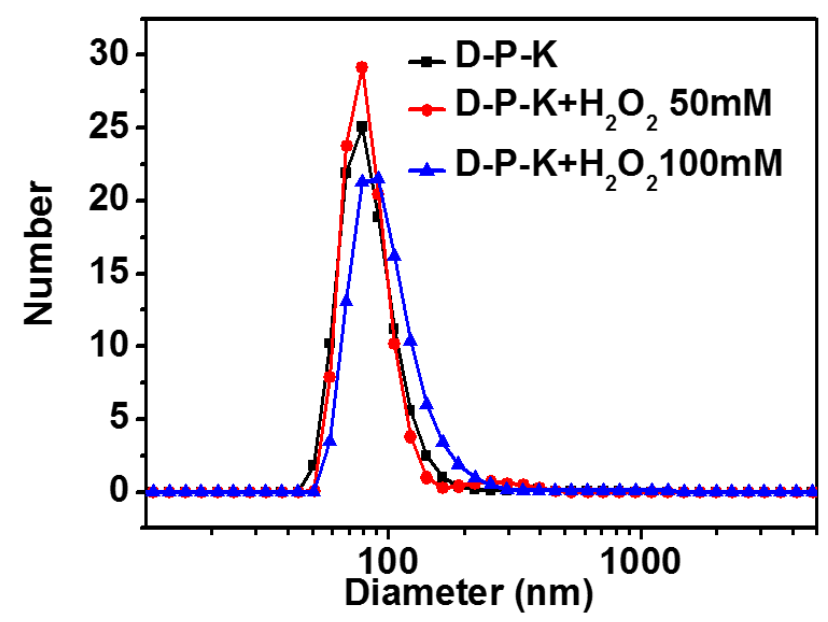

Figure S6. Number size distribution of D-P-K nanoparticles in PB solution and in 50 $\mathrm{mM} / 100 \mathrm{mM} \mathrm{H}_{2} \mathrm{O}_{2}$ measured by DLS. 


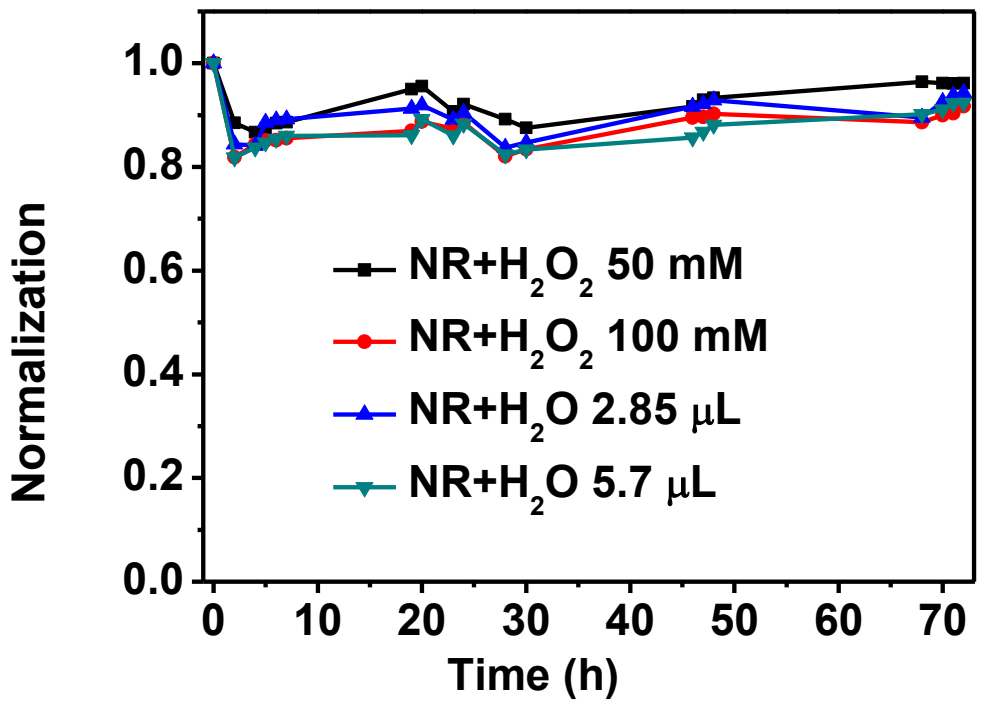

Figure S7. Incubation time-dependent change in the normalized fluorescence intensity of $\mathrm{NR}$ in $\mathrm{EtOH}(0.5 \mathrm{~mL})$ at different concentrations of $\mathrm{H}_{2} \mathrm{O}_{2}$. The deionized water with the same volume $(2.85 \mu \mathrm{L}$ for $50 \mathrm{mM}$ and $5.7 \mu \mathrm{L}$ for $100 \mathrm{mM})$ was added as control group.

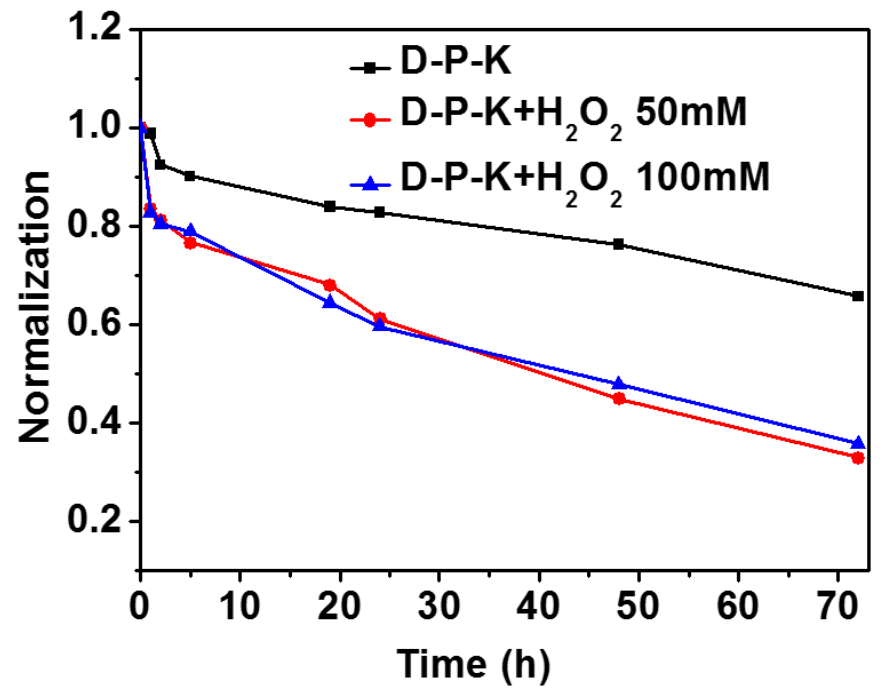

Figure S8. Incubation time-dependent change in the normalized fluorescence intensity of NR in D-P-K nanoparticles at different concentration of $\mathrm{H}_{2} \mathrm{O}_{2}$. 


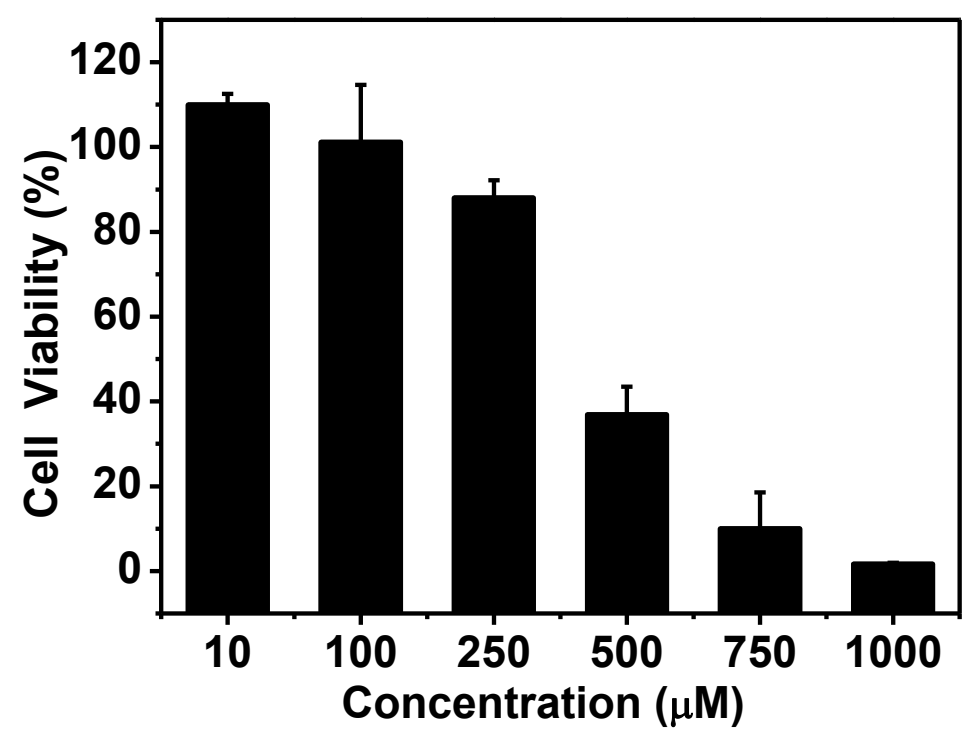

Figure S9. Viability of U87 cells incubated with free KLAK measured by the CCK-8 assay. Results are presented as the mean \pm SD in triplicate.

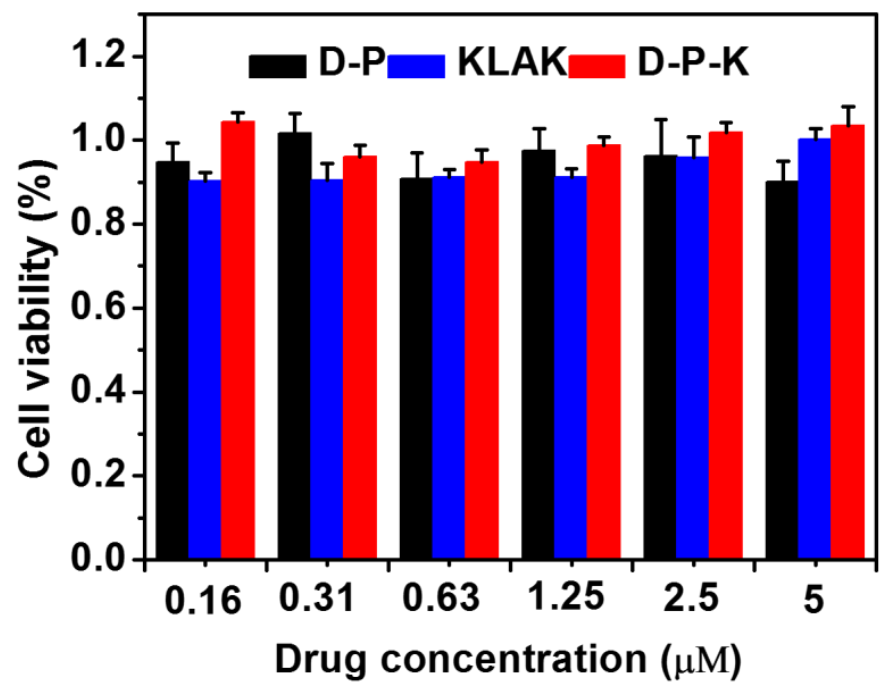

Figure S10. Viability of U87 cells incubated with D-P-K, KLAK and D-P measured by the CCK-8 assay. Results are presented as the mean \pm SD in triplicate. 


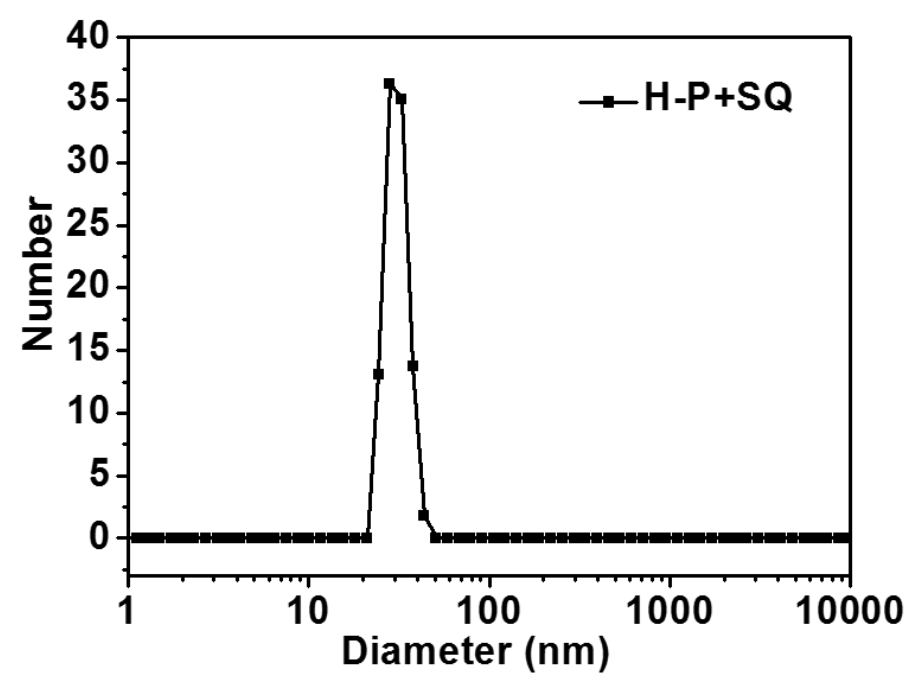

Figure S11. Number size distribution of SQ loaded H-P nanoparticles in PB solution measured by DLS.

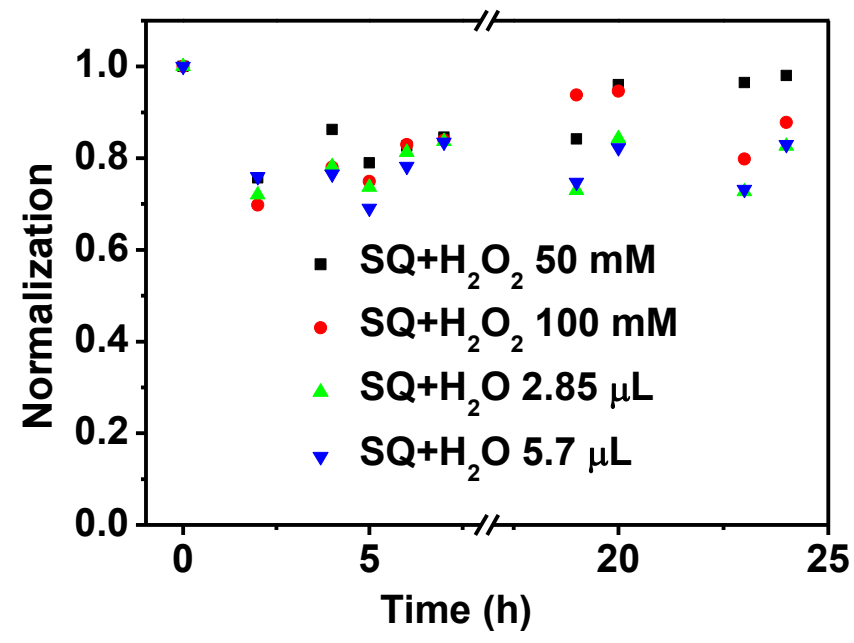

Figure S12. Incubation time-dependent change in the normalized fluorescence intensity of SQ in DMSO $(0.5 \mathrm{~mL})$ at different concentrations of $\mathrm{H}_{2} \mathrm{O}_{2}$. The deionized water with the same volume $(2.85 \mu \mathrm{L}$ for $50 \mathrm{mM}$ and $5.7 \mu \mathrm{L}$ for $100 \mathrm{mM})$ was added as control group. 